Benjamin Kickhöfer, Friederike Hülsmann, Regine Gerike, Kai Nagel

\title{
Rising car user costs: comparing aggregated and geo-spatial impacts on travel demand and air pollutant emissions
}

Chapter in book | Submitted manuscript (Preprint)

This version is available at https://doi.org/10.14279/depositonce-7731

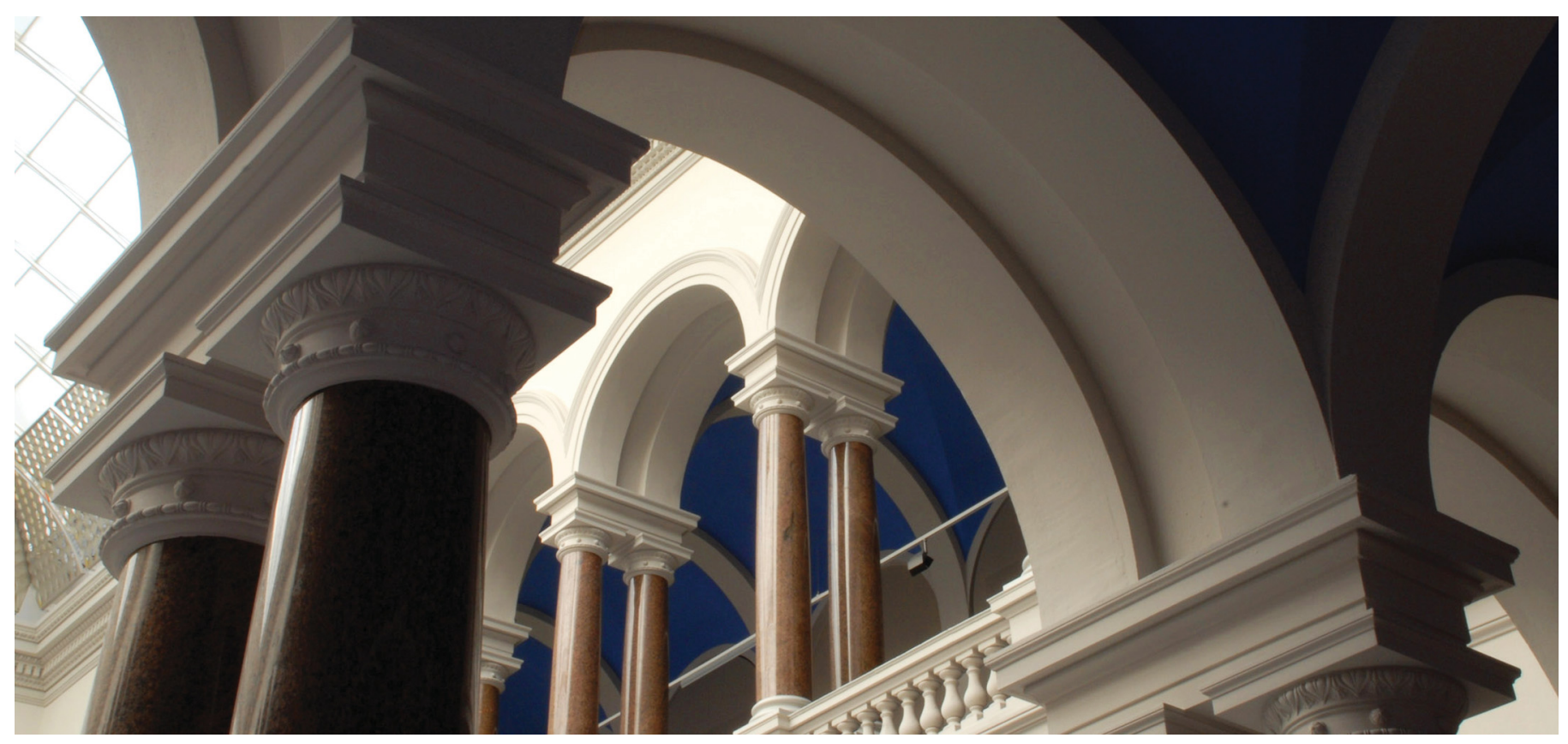

This is a draft chapter / article. The final version is available in "Smart transport networks : market structure, sustainability and decision making" edited by Vanoutrive, T., Verhetsel, A., published in 2013, Edward Elgar Publishing Ltd http://dx.doi.org/10.4337/9781782548331.00014

The material cannot be used for any other purpose without further permission of the publisher, and is for private use only.

Kickhöfer, B.; Hülsmann, F.; Gerike, R.; Nagel, K. (2013). Rising car user costs: comparing aggregated and geo-spatial impacts on travel demand and air pollutant emissions. Smart Transport Networks, 180 207. https://doi.org/10.4337/9781782548331.00014 


\title{
Rising car user costs: comparing aggregated and geo-spatial impacts on travel demand and air pollutant emissions
}

\author{
Benjamin Kickhöfer ${ }^{a}$, Friederike Hülsmann ${ }^{b},{\text { Regine } \text { Gerike }^{b} \text {, Kai Nagel }}^{a}$ \\ ${ }^{a}$ Transport Systems Planning and Transport Telematics \\ Berlin Institute of Technology (TU Berlin) \\ Correspondence address: kickhoefer@vsp.tu-berlin.de \\ ${ }^{b}$ Research Centre Mobility and Transport \\ Technische Universität München
}

29.02 .2012

\begin{abstract}
When estimating future transportation costs for car users, there is some agreement that these costs are likely to increase over the upcoming decades. The reasons are multifaceted: rising prices for crude oil, large investments in alternative energy supply and in corresponding demand-side infrastructure as well as road pricing schemes or taxes in order to internalize negative external effects of road traffic. Rising costs are likely to change aggregated air pollutant emissions as well as their spatial distribution. Especially in urban areas where demand for road traffic is high, a reduction of air pollutant emissions could mitigate the negative impacts on human health and the environment. It is likely that rising car user costs lead to such a reduction in car travel demand. However, it is still an open question whether congestion relief, in addition to the impact of a decrease in demand, yields potentials for lowering local air pollutant emissions.

For this purpose, a real-world scenario of the Munich metropolitan area in Germany is set up and simulated with the large-scale multi-agent microsimulation MATSim. The software is capable of simulating complete daily plans of several million individuals and allows emission calculations on a detailed level, e.g. for a single street or a single vehicle over the time of day. Varying emission levels resulting from different vehicle characteristics, road categories, speed levels, and traffic situations are considered. By mapping emissions back to the emission source, i.e. the road segment, a spatial analysis of air pollutant emissions is performed, identifying areas with high car travel demand and the resulting changes in emissions due to a decrease in demand.

We find that car user price elasticities of demand for different subpopulations, including inner-urban travelers and commuters, are in a reasonable range. Price elasticities of emissions turn out to be higher than those of demand. This implies that when car user costs rise, the reduction of air pollutant emissions is higher than the decrease in car travel demand. In a more disaggregated analysis, we obtain that congestion relief is likely to lower emissions per vehicle kilometer on urban roads. However, we also find that congestion relief can lead to higher emissions per vehicle kilometer for high-speed arterials or tangential motorways.
\end{abstract}

Keywords: emission modeling, price elasticities, spatial analysis, urban transport, user costs, agent-based modeling

Preferred citation style: Kickhöfer, B., F. Hülsmann, R. Gerike, and K. Nagel (2013). "Rising car user costs: comparing aggregated and geo-spatial impacts on travel demand and air pollutant emissions". In: Smart Transport Networks: Decision Making, Sustainability and Market Structure. Ed. by T. Vanoutrive and A. Verhetsel. NECTAR Series on Transportation and Communications Networks Research. Edward Elgar Publishing Ltd, pp. 180-207. ISBN: 978-1-78254-832-4. 


\section{Introduction}

Our paper starts from the assumption that car user costs are about to increase in the upcoming decades. This is likely to have impacts on aggregated air pollutant emissions and on the spatial distribution of emissions. The concentration of some air pollutants still exceeds the limiting values prescribed by the European Union, especially in urban areas. Thus, the main focus of this paper is the question whether a decrease in car travel demand due to higher user costs would result in a over-proportional reduction of air pollutant emissions. When it comes to the discussion of cost-related transport policies, large-scale transport models are needed. However, for the analysis of air pollutant emissions, a detailed investigation of the micro-level is also necessary. In order to combine both objectives, we use a multi-agent transport model for our simulations. The multi-agent transport simulation MATSim ${ }^{1}$ is able to simulate large-scale scenarios. It is also particularly suitable for calculating air pollutant emissions on a detailed level as complete daily plans are modeled and the traveler's identity is kept throughout the simulation process. For illustration purposes of the impacts on air pollutant emissions, nitrogen dioxide $\left(\mathrm{NO}_{2}\right)$ is chosen. Furthermore, the transport sector is the main source of $\mathrm{NO}_{2}$ emissions and $\mathrm{NO}_{2}$ concentration limits are still often exceeded.

The paper starts with a presentation of the transport model in Sec. 2.1, followed by a description of the emission modeling tool in Sec. 2.2. Sec. 3 consists of three parts: first, a presentation of the Munich base scenario; second, a description of the simulation approach and a definition of four policy scenarios; and third, the validation of the base scenario with respect to modal split and traffic volumes. In Sec. 4, aggregated car user price elasticities of different subpopulations (inner-urban traffic, commuter, and inverse commuter) are calculated and discussed. Furthermore, car travel demand as well as $\mathrm{NO}_{2}$ emissions are analyzed on a spatially disaggregated level for all scenarios. The paper ends with a conclusion in Sec 5 .

\section{Methodology}

This section (i) gives a brief overview of the general simulation approach of MATSim and (ii) shortly describes the emission modeling tool that is developed by the authors. Within the present paper, only general ideas will be presented. For further information please refer to Raney and Nagel [2006] and the Appendix or to Hülsmann et al. [2011], respectively.

\subsection{Transport Simulation with MATSim}

In MATSim, each traveler of the real system is modeled as an individual agent. The approach consists of an iterative loop that has the following steps:

1. Plans generation: All agents independently generate daily plans that encode among other things their desired activities during a typical day as well as the transport mode for every intervening trip.

2. Traffic flow simulation: All selected plans are simultaneously executed in the simulation of the physical system.

3. Evaluating plans: All executed plans are evaluated by a utility function which encodes in this paper the perception of travel time and monetary costs for the available transport modes.

4. Learning: Some agents obtain new plans for the next iteration by modifying copies of existing plans. This modification is done by several modules that correspond to the available choice dimensions. In the present paper, agents adapt their routes only for car trips. Furthermore, they can switch between the modes car and public transport (pt). The choice between plans is performed with respect to a Random Utility Model.

\footnotetext{
1 "Multi-Agent Transport Simulation", see www.matsim.org
} 
The repetition of the iteration cycle coupled with the agent database enables the agents to improve their plans over many iterations. This is why it is also called learning mechanism (see Appendix). The iteration cycle continues until the system has reached a relaxed state. At this point, there is no quantitative measure of when the system is "relaxed"; we just allow the cycle to continue until the outcome is stable.

\subsection{Emission Modeling Tool}

There are several sources of air pollution that can be assigned to road traffic: Warm emissions are emitted when the vehicle's engine is already warmed-up, whereas cold-start emissions occur during the warm-up phase. Warm emissions differ with respect to driving speed, acceleration and stop duration as well as vehicle characteristics including vehicle type, fuel type, cubic capacity and Euro class [André and Rapone, 2009]. Cold emissions differ with respect to distance traveled, parking time, average speed, ambient temperature and vehicle characteristics [Weilenmann et al., 2009]. Furthermore, emissions also result from evaporation and air conditioning. Due to their small contribution to the overall emission level, this last source is not considered in the present paper.

The calculation of warm emissions is composed of two steps: first, kinematic characteristics and vehicle attributes are deduced from the MATSim simulation output. Then, this information is used in order to extract emission factors from a database. MATSim exhibits activity chains for every agent over the entire day. Whenever an agent enters or leaves a road segment a time stamp is created. Thereby, it is possible to calculate the free flow travel time and the travel time in a loaded network for every agent and road segment. As MATSim keeps demographic information until the system is relaxed, information about each agent's vehicle is available at any time. Vehicle attributes are derived from survey data (see Sec. 3.1) and comprise vehicle type, age, cubic capacity and fuel type. They can, therefore, be used for very differentiated emission calculations. Where no detailed information about vehicle type is available, fleet averages for Germany are used.

Having identified the above kinematic characteristics for a road segment, specific travel behavior resulting from such data is assigned by using the detailed handbook of emission factors called HBEFA ${ }^{2}$. For some European countries including Germany, the handbook contains country specific emission factors that can vary by vehicle characteristics, road category, gradient and speed limit. The handbook provides further disaggregated emission factors depending on four traffic situations: free flow, heavy, saturated and stop\&go. Such traffic situations are described by kinematic characteristics, which are deduced from driving cycles, i.e. time-velocity profiles. Typical driving cycles form the basis for calculating traffic situations and, thus, typical emission factors in HBEFA.

In order to assign emission factors to the traffic flows generated by MATSim, the driving behavior of an agent on a certain road segment in the MATSim simulation is linked to the respective HBEFA driving cycle. Therefore, each road segment is divided into two parts representing stop\&go and free flow traffic situations. A similar methodology was developed by Hatzopoulou and Miller [2010] who, in a more simple approach, assume fixed exhaust emissions per time unit. The present paper uses a more detailed calculation based on different traffic situations: it is based on the assumption that cars role in free flow until they have to wait in the queue where a stop\&go traffic situation applies. The length of the queue depends on the traffic demand on the road. If demand is higher than the capacity of a road segment, a queue emerges where stop\&go is assumed. Another reason for the segmentation of a road segment into free flow and stop\&go parts is due to the marginal difference between the emission factors of free flow, heavy and saturated. In contrast to these three traffic situations, the emission factors of stop\&go are around twice as high. The difference between actual travel time and free flow travel time per road segment corresponds to travel time spent in stop\&go. The average speed of stop\&go that represents a kinematic characteristic of the typical stop\&go driving behavior can be obtained from the HBEFA database. The stop\&go average speed and travel time is used to calculate

\footnotetext{
2 "Handbook Emission Factors for Road Transport", Version 3.1, see www.hbefa.net
} 
the queue length. The respective emission factors can be assigned to the resulting stop\&go and free flow fractions. The implementation of the approach has been evaluated in a test scenario, which compared real traffic data with MATSim simulations for a single road segment. For a more detailed description of the emission modeling tool, please refer to Hülsmann et al. [2011].

Regarding cold-start emissions, HBEFA provides the relevant factors for passenger cars only. The application of the relevant cold-start emission factor depends on two attributes: distance traveled and parking time. The latter is calculated by subtracting the time stamp when the activity starts from the time stamp when the activity ends. The subsequent distance traveled is determined by aggregating the lengths of all road segments the agent drives along until the next activity is reached. The longer the parking time and the accumulated distance, the higher the cold-start emission factor.

In order to further process the warm and cold-start emissions, so-called emission events are generated and further segmented into a warm pollution and cold-start pollution emission event. The former describes the warm emissions for each person and road segment and adds a time stamp. Cold-start pollution is given for each person and the road segment on which the trip starts. The definition of emission events follows the MATSim framework that uses events for storing disaggregated information in XML-format (see Appendix).

\section{Scenario: Munich, Germany}

The methodology described in Sec. 2 is now applied to a large-scale scenario of the Munich metropolitan area with about two million individuals. For this purpose, a scenario needs to be set up based on network and survey data. The process is described in Sec. 3.1, followed by a specification of the simulation procedure in Sec. 3.2 and a validation in Sec. 3.3 where it is discussed to what extent the simulation reproduces reality.

\subsection{Setting up the Scenario}

Network (supply side) Network data was provided by the municipality of Munich [RSB, 2005]. The data matches the format of the aggregated static transport planning tool VISUM ${ }^{3}$. It represents the road network of the federal state Bavaria, being more detailed in and around the city of Munich and less detailed further away. It consists of 92'259 nodes and 222'502 connecting edges $(=$ links). Most road attributes, such as free speed, capacity, number of lanes, etc. are defined by the road type. Only geographical position and length are attributes of each single link. This data is converted to MATSim format by taking length, free speed, capacity, number of lanes, and road type from VISUM data. VISUM road capacities are meant for 24-hour origin-destination matrices. Since the network is almost empty during night hours, peak hour capacity is set to VISUM capacity divided by 16 (not 24). This results in an hourly capacity of about 2000 vehicles per lane on an urban motorway. In order to speed up computation, some road categories corresponding to small local roads are removed from the network. Furthermore, nodes with only one ingoing and one outgoing link are removed. The two resulting links are then merged, bringing the size of the network down to 17'888 nodes and 41'942 links. When merging, the two link lengths are summed up; free speed is calculated based on the minimal time needed for passing the original links; capacity is set to the minimum of the two links; the number of lanes is calculated based on the number of vehicles that fit on the two original links; and finally the road type - important input for emission calculations - is set to the one of the outgoing link.

Population (demand side) In order to obtain a realistic time-dependent travel demand, several data sources are converted into the MATSim population format. The level of detail of the resulting individual daily plans naturally depends on the information available from either disaggregated stated preference data or aggregated population statistics. Therefore, three subpopulations are created, each corresponding to one of the three different data sources:

\footnotetext{
3 "Verkehr In Städten UMlegung" developed by PTV AG (see www.ptv.de)
} 
- Inner-urban traffic (based on Follmer et al. [2004]):

The synthetic population of Munich is created on the base of very detailed survey data provided by the municipality of Munich RSB [2005], named "Mobility in Germany" (MiD 2002). In the area of the Munich municipality, 3612 households (with 7206 individuals) were interviewed. The data consists of different data sets such as household data, person specific data and trip data. A detailed description of survey methods and data structure can be found in Follmer et al. [2004]. Individuals were asked to report their activities during a complete day including activity locations, activity start and end times as well as the transport mode for the intervening trips. Due to privacy protection, not the exact coordinates of activity locations are available, but only the corresponding traffic analysis zones (1066 zones in total). For the generation of the synthetic MATSim population, individual activity locations are distributed randomly within these zones. Furthermore, all incomplete data sets are removed, e.g. when the location or the starting times of one activity is missing in the survey. The transport modes train and bus are treated as public transport trips, motorbikes and mopeds are treated as car trips. The transport modes ride (= in car as passenger), bike and other (= unknown) are kept for the initial MATSim population. Overall, the data cleaning results in 3957 individuals, the representative sample for demand generation. Finally, these agents are "cloned" while holding activity transport analysis zones constant but finding new random locations within these zones for every clone. This process is performed until the population reaches the real-world size of 1.4 million inhabitants. Thus, the synthetic population living inside the Munich municipality boundaries consists for this study of 1'424'520 individuals.

MiD 2002 also provides detailed vehicle information for every household. Linking this data with individuals makes it possible to assign a vehicle to a person's car trip and thus, calculating emissions based on this detailed information. As of now there is, however, no vehicle assignment module which models intra-household decision making. It is, therefore, possible that a vehicle is assigned to more than one person at the same time.

- Commuter Traffic (based on Böhme and Eigenmüller [2006]):

Unfortunately, the detailed data for the municipality of Munich does neither contain information about commuters living outside of Munich and working in Munich nor about people living in Munich and working outside of Munich. The data analyzed by Böhme and Eigenmüller [2006] provides information about workers that are subject to the social insurance contribution with the base year 2004. Origin and destination zones are classified corresponding to the European "Nomenclature of Statistical Territorial Units" (NUTS) ${ }^{4}$, level 3. Thus, the origin-destination flows between Munich and all other municipalities in Germany are available. Neither departure times nor transportation mode are, however, provided. The total number of commuters tends to be underestimated since public servants and education trips are not included in this statistic. Therefore, every origin-destination relation is increased by the factor 1.29 [Guth et al., 2010]. Initially, car trips are assumed to $67 \%$ of the total commuter trips, public transport to $33 \%$ [MVV, 2007]. Departure times are set so that people arrive at their working place, according to a normal distribution with $N(8$ a.m., 2 hours $)$ when routed on an empty network. Work end times are set to nine hours after the arrival at the working place. This results overall in 510'150 commuters from which 306'160 people have their working place in Munich. All these MATSim agents perform a daily plan that encodes two trips: from their home location to work and back. Due to this simplification, they are the first contribution to "background traffic", as it will be addressed from here on.

- Commercial Traffic (based on ITP/BVU [2005]):

The second contribution to "background traffic" is given by commercial traffic with the base year 2004. On behalf of the German Ministry of Transport, ITP/BVU [2005] published the origin-destination commodity flows throughout Germany differentiated by mode

\footnotetext{
${ }^{4}$ See http://epp.eurostat.ec.europa.eu/portal/page/portal/nuts_nomenclature/introduction, last access 18.02.2011
} 
and ten groups of commodities. Origin and destination zones inside Germany are classified corresponding to NUTS 2, and outside Germany to NUTS 3 level, respectively. The number of trucks ( $>3.5$ tons) between two zones or within a zone is calculated based on the commodity flow in tons and the average loading of trucks. ${ }^{5}$ The starting and ending points of the trips are - due to the lack of more detailed data - randomly distributed inside the origin and destination zone, respectively. The resulting MATSim agents obtain a plan that only consists of two activities with one intervening trip. Departure times are set so that the number of "en-route vehicles" in the simulation matches a standard daily trend for freight vehicles. ${ }^{5}$ For this scenario, trips are only considered if they are carried out at least once in Bavaria during the day. This results in 158'860 agents with one single commercial traffic trip.

Overall, the synthetic population now consists of 2'093'530 agents. To speed up computations, a $10 \%$ sample is used in the subsequent simulations; other studies indicate that this seems to be an appropriate percentage in order to achieve results close enough to reality (see e.g. Chen et al. [2008]). For background traffic, no detailed vehicle information is available. Emissions are, therefore, calculated with the help of fleet averages for cars and trucks from HBEFA.

\subsection{Simulation Approach}

Choice Dimensions For the mental layer within MATSim which describes the behavioral learning of agents, a simple utility based approach is used in this paper. When choosing between different options with respect to a Random Utility Model, agents are allowed to adjust their behavior among two choice dimensions: route choice and mode choice. The former allows individuals to adapt their routes on the road network when going by car. The latter makes it possible to change the transport mode for a sub-tour (see Appendix) within the agent's daily plan. Only a switch from car to public transport or the other way around is possible. Trips that are initially done by any other mode remain fixed within the learning cycle. From a research point of view, this approach can be seen as defining a system where public transport is a placeholder for all substitutes of the car mode.

Utility Functions In the calculations for the travel related part of utility (see Eq. 6 in the Appendix), travel time and monetary distance costs are considered as attributes of every car and public transport trip. Due to the lack of data of the municipality of Munich, the utility parameters are taken from Kickhöfer [2009] who based the estimations on data from Switzerland provided by Vrtic et al. [2008]. The initial formulation of the utility functions for these estimations is as follows:

$$
\begin{aligned}
& V_{c a r, i, j}=\beta_{0}+\beta_{t r, c a r} \cdot t_{i, c a r}+\beta_{c o s t, c a r} \cdot c_{i, c a r} \\
& V_{p t, i, j}=\beta_{t r, p t} \cdot t_{i, p t}+\beta_{c o s t, p t} \cdot c_{i, p t},
\end{aligned}
$$

where $t_{i}$ is the travel time of the trip to activity $i$ and $c_{i}$ is the corresponding monetary cost. Travel times and monetary costs are mode dependent, indicated by the indices. The utilities $V_{c a r, i, j}$ and $V_{p t, i, j}$ for person $j$ are computed in "utils". Estimating the parameters ${ }^{6}$

$\hat{\beta}_{t r, c a r}=-2.26 / h, \quad \hat{\beta}_{t r, p t}=-2.36 / h, \quad \hat{\beta}_{\text {cost }, \text { car }}=-0.2 / m U, \quad \hat{\beta}_{\text {cost }, p t}=-0.0535 / m U$

and splitting the time related parameters into opportunity costs of time and additional disutility caused by traveling (see e.g. Kickhöfer et al. [2011]), leads to the functional form ${ }^{7}$ for the overall

\footnotetext{
${ }^{5}$ Estimations are based on personal correspondence with Dr. Gernot Liedke from Karlsruhe Institute of Technology (October, 2010).

${ }^{6}$ Estimated parameters are in this paper flagged by a hat. $h$ is one hour and $m U$ is a unit of money.

7 The alternative specific constant $\beta_{0}$ (see e.g. Train [2003]), is estimated not significantly different from zero and is, therefore, not considered in the functional form of the utility functions. This essentially means that no general a-priori preference for one of the transport modes can be found in the data.
} 
utility of an activity:

$$
\begin{aligned}
V_{c a r, i, j} & =+\frac{2.26}{h} t_{*, i} \cdot \ln \left(\frac{t_{p e r f, i}}{t_{0, i}}\right)-\frac{0.2}{m U} \cdot c_{i, c a r} \\
V_{p t, i, j} & =+\frac{2.26}{h} t_{*, i} \cdot \ln \left(\frac{t_{p e r f, i}}{t_{0, i}}\right)-\frac{0.0535}{m U} \cdot c_{i, p t}-\frac{0.1}{h} \cdot t_{i, p t},
\end{aligned}
$$

In this paper, $c_{i, c a r}$ and $c_{i, p t}$ are calculated for every trip by multiplying the distance between activity locations $i-1$ and $i$ by a specific out-of-pocket distance cost rate for car and public transit (see below). For the functional form of the positive utility earned by performing an activity, please refer to Eq. 7 in the Appendix. Because of the argument regarding the opportunity cost of foregone activity time when arriving early (see Appendix), the effective marginal disutility of early arrival is $\hat{\beta}_{\text {earlyeff }}=-\hat{\beta}_{\text {perf }} \cdot t_{*, i} / t_{\text {perf }, i} \approx-\hat{\beta}_{\text {perf }}=-2.26 / h$ which is equal to the effective marginal disutility of traveling with car $\hat{\beta}_{t r, c a r_{\text {eff }}}$. The effective marginal disutility of traveling by pt is, by the same argument, $\hat{\beta}_{t r, p t_{e f f}}=-\hat{\beta}_{\text {perf }} \cdot t_{*, i} / t_{\text {perf }, i}-\left|\hat{\beta}_{t r, p t}\right| \approx-\hat{\beta}_{\text {perf }}-\left|\hat{\beta}_{t r, p t}\right| \approx-2.36 / h$.

As a result of this simulation approach, it is possible to observe mode reactions to price increases and to derive price elasticities of demand.

Simulation Procedure For 800 iterations, $15 \%$ of the agents perform route adaption (discovering new routes), $15 \%$ change the transport mode for a car or pt sub-tour in their daily plan and $70 \%$ switch between their existing plans. Between iteration 801 and 1000 route and mode adaption is switched off; in consequence, agents only switch between existing options. The output of iteration 1000 is then used as input for the continuation of the base case and the four different policy cases:

- Base case: car user costs remain constant at $10 \mathrm{ct} / \mathrm{km}$

- Policy case 1: increasing car user costs by $25 \%$ to $12.5 \mathrm{ct} / \mathrm{km}$

- Policy case 2: increasing car user costs by $50 \%$ to $15 \mathrm{ct} / \mathrm{km}$

- Policy case 3: increasing car user costs by $75 \%$ to $17.5 \mathrm{ct} / \mathrm{km}$

- Policy case 4: increasing car user costs by $100 \%$ to $20 \mathrm{ct} / \mathrm{km}$

User costs for public transport are assumed to be constant at $17 \mathrm{ct} / \mathrm{km}$ for all policy cases. Please note, that the term "user costs" is referred to as out-of-pocket costs for the users. All simulation runs are continued for another 500 iterations. Again, during the first 400 iterations $15 \%$ of the agents perform route adaption while another $15 \%$ of agents choose between car and public transport for one of their sub-tours. The remaining agents switch between existing plans. For the final 100 iterations only a fixed choice set is available for all agents. When evaluating the impact of the car user cost increases, the final iteration 1500 of every policy case is compared to iteration 1500 of the base case.

\subsection{Verification of the Base Case}

Modal Split While converting the input data described by Follmer et al. (2004) into the MATSim synthetic population (see Sec. 3.1), some individuals were omitted due to a lack of coordinates or activity times. Therefore, Table 1 shows differences in the modal split over all trips comparing the input data with the synthetic subpopulation at iteration 0 and 1500 . Note that only the mode share of the subpopulation traveling within Munich is shown. As one can see, the initial synthetic population overestimates the percentage of walk trips by $2.55 \%$ and of bike trips by $2.05 \%$, while underestimating the percentage of car trips by $3.52 \%$ and of ride trips by $1.61 \%$. Public transport trips remain almost unchanged and the unknown mode is not discussed further due to the small number of trips. The error seems to be acceptable since no major differences occur. 
Table 1: Trips per transport mode as percentage of total trips; Comparison between input data (Follmer et al., 2004) and the MATSim synthetic subpopulation.

\begin{tabular}{clllll}
\hline \hline mode & $\begin{array}{l}\text { Follmer } \\
\text { al. (2004) }\end{array}$ & $\begin{array}{l}\text { Synthetic } \\
\text { population } \\
\text { it.0 }\end{array}$ & $\begin{array}{l}\text { Synthetic } \\
\text { population } \\
\text { it.1500 }\end{array}$ & $\begin{array}{l}\text { difference } \\
\text { it.0 }\end{array}$ & $\begin{array}{l}\text { difference } \\
\text { it.1500 }\end{array}$ \\
\hline bike & 10 & 12.05 & 12.05 & +2.05 & +2.05 \\
car & 26 & 22.48 & 20.88 & -3.52 & -5.12 \\
pt & 22 & 21.98 & 23.59 & -0.02 & +1.59 \\
ride & 13 & 11.39 & 11.39 & -1.61 & -1.61 \\
undefined & 0 & 0.55 & 0.55 & +0.55 & +0.55 \\
walk & 29 & 31.55 & 31.55 & +2.55 & +2.55 \\
\hline
\end{tabular}

When the system is in a relaxed state, car trips are even more underestimated, whereas public transport trips are overestimated compared to iteration 0 . Reasons might be the missing location choice module and the assumptions regarding the specification of the utility function. Overall, the additional increase in public transport and decrease in car trips amounts only to $1.6 \%$. Thus, the synthetic MATSim population seems to be a good starting point for analyzing the change in travel demand and air pollutant emissions due to rising car user costs.

Comparison to Counting Stations Before analyzing demand and emission reductions, the realism of the executed plans in the simulation is verified. The interaction of individuals on the physical representation of the road network is simulated over 1500 iterations as described in Sec. 2.1. After reaching a stable outcome, some kind of measurement must exist to determine the quality of the simulation output. For the Munich region, data from 166 traffic counting stations is available and aggregated for every hour over time of day.

Volumes 14:00 - 15:00, Iteration: 1500

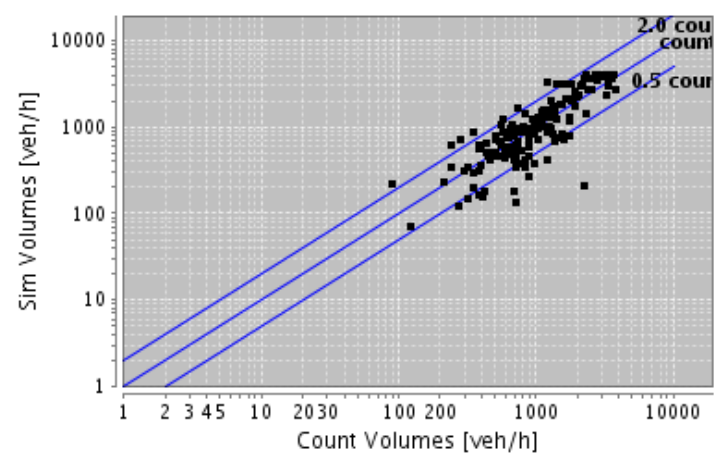

(a) Comparison for one hour (2 p.m to 3 p.m.)

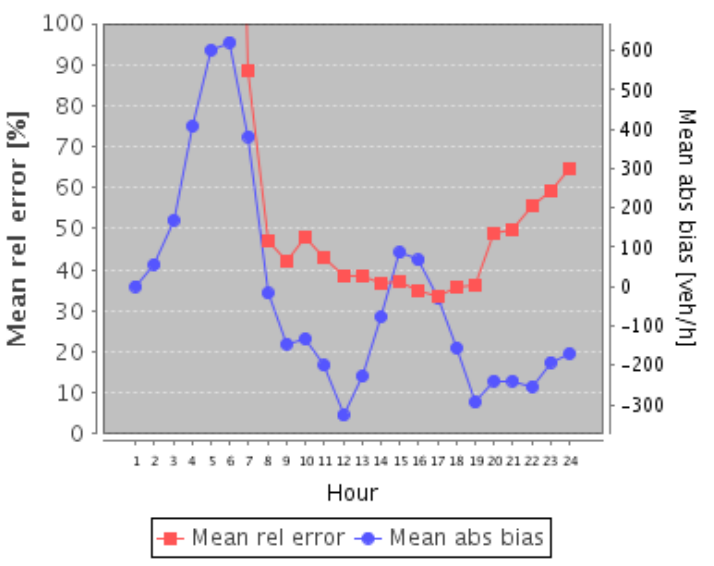

(b) Hourly analysis over time of day

Figure 1: Realism of the simulation results. 166 traffic counting stations provide real-world traffic counts for the Munich municipality area.

The best quality of this data is available for Thursday, January $10^{\text {th }} 2008$. It is now used to compare simulated traffic volumes to real-world values. Different statistical values can be calculated, such as mean relative error or mean absolute bias. Fig. 1 shows two examples of standard reports that MATSim automatically generates: Fig. 1a depicts the comparison for one hour and all counting stations. If all data points were on a 45 degree line, the simulation would nicely reproduce reality. However, as one can see, there are errors between simulated and real values. The mean relative error for every sensor is a good indicator for the overall fit of the simulation. It is calculated as:

$$
M R E=\left|\frac{Q_{\text {sim }}-Q_{\text {real }}}{Q_{\text {real }}}\right|,
$$


where $Q_{\text {sim }}$ indicates the simulated and $Q_{\text {real }}$ the real-world vehicle flow over the corresponding counting station in the corresponding hour. Averages for a given hour are obtained by averaging over all sensors. In the example shown in Fig. 1b, the simulation deviates strongly from reality during night hours, i.e. from midnight until 7 a.m. During daytime, i.e. from 7 a.m. until the evening, the hourly mean relative error is between $30 \%$ and $50 \%$ with better values in the afternoon.

In order to reach this accuracy, some adjustments were done, e.g. varying the parameters of the normal distribution that describe work arrival time peak and variance for commuters (see Sec. 3.1). For now, since this is meant to be a research scenario, the quality of the simulations seems to be adequate. However, by further optimizing travel demand and network information, better values for the mean relative error can be obtained as Chen et al. [2008] or Flötteröd et al. [2011] showed for a scenario of Zurich, Switzerland.

\section{The Relationship between Car Travel Demand and Air Pollutant Emissions}

This section aims at investigating two research questions: (i) "Are price elasticities of emissions higher than those for car travel demand?", and if yes, (ii) "Can a spatial effect be observed?". In Sec. 4.1, we derive overall price elasticities of car travel demand from the simulation and then compare these to price elasticities of $\mathrm{NO}_{2}$ emissions. In Sec. 4.2, we first identify areas with high travel demand in the city of Munich using a more disaggregated approach. In a second step, we present a spatial analysis of absolute changes in demand and $\mathrm{NO}_{2}$ emissions due to policy case 4. Then, we investigate the role of absolute changes in emissions per vehicle kilometer following the same spatial analysis.

\subsection{Aggregated Price Elasticities}

Possible reactions of car users to increasing distance costs comprise, in the present paper, either choosing shorter but eventually more time consuming routes or changing the transport mode to public transport, the placeholder for all substitutes to car.

Fig. 2 shows the daily demand for vehicle kilometers traveled $(v \mathrm{~km})$ over different distance cost factors (from $10 \mathrm{ct} / \mathrm{km}$ for the base case up to $20 \mathrm{ct} / \mathrm{km}$ for the highest policy case). The reduction in demand is presented for three different subpopulations (see Sec. 3.1): black circles correspond to inner-urban traffic, red rectangles and green crosses to inverse commuter and commuter, respectively. The inner-urban demand for vehicle kilometers traveled drops from about $400^{\prime} 000 \mathrm{vkm}$ in the base case by $18 \%$ to roughly $333^{\prime} 000 \mathrm{vkm}$ in the highest policy case. Much larger reductions in car travel demand are observed for the other subpopulations: car travel demand of inverse commuters drops from $1^{\prime} 650^{\prime} 000 \mathrm{vkm}$ by $54 \%$ to $754^{\prime} 000 \mathrm{vkm}$, and for commuters from $4^{\prime} 624^{\prime} 000 \mathrm{vkm}$ by $72 \%$ to $1^{\prime} 290^{\prime} 000 \mathrm{vkm}$. The big difference between innerurban demand and (inverse) commuters is due to the much longer distances traveled by the last two groups where the car mode gets extremely unattractive. Travel demand reactions for freight traffic is not shown since this subpopulation is not allowed to change from car (or truck) to public transport. The figure also provides linear regression lines including their functional forms for every subpopulation. Even though, especially for commuter traffic, a linear regression obviously does not lead to the best fit (one can nicely see the "inverse-S-shape" produced by the logit model), it is still quite appropriate in order to derive constant price elasticities.

Choosing $p_{0}=10 \mathrm{ct} / \mathrm{km}$ as operating point, price elasticities of demand can directly be derived for every policy case $i$, using:

$$
\eta_{q, p}=\frac{\frac{q_{i}-q_{0}}{q_{0}}}{\frac{p_{i}-p_{0}}{p_{0}}},
$$

where $q_{i}$ is the travel demand at price level $p_{i}$. In order to describe the overall relationship between user costs and car travel demand, a constant price elasticity can be derived using the regression functions: 


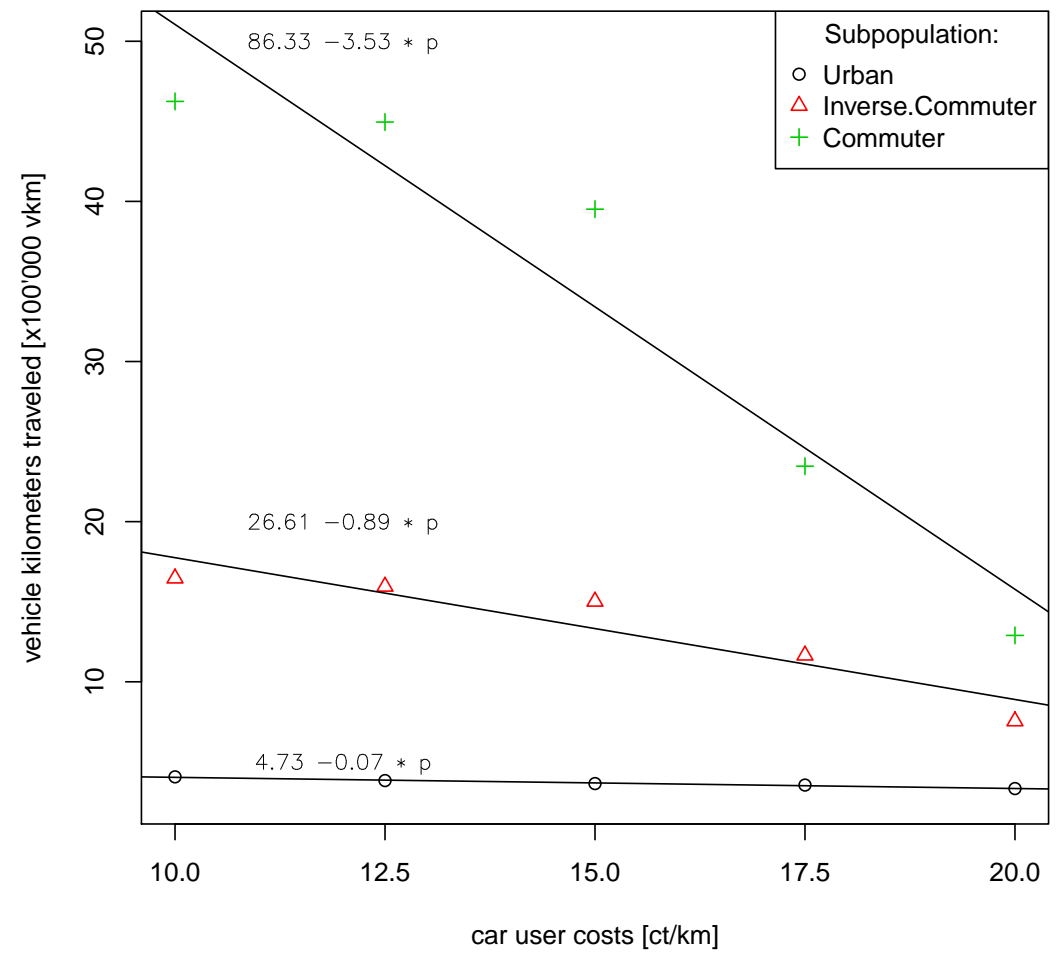

Figure 2: Overall daily vehicle kilometers traveled for the base case and the four policy cases by subpopulation: simulated values and estimations as linear regression functions; values for a representative $10 \%$ sample.

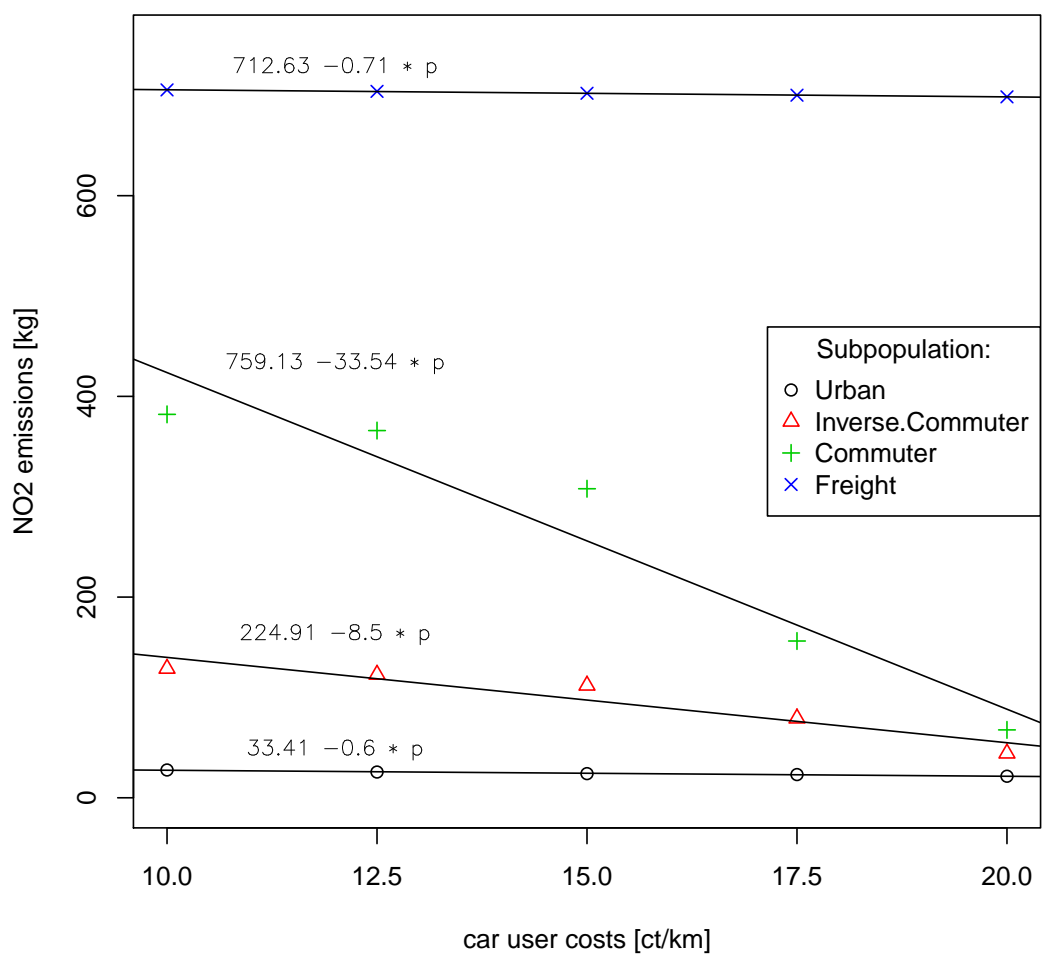

Figure 3: Overall daily $\mathrm{NO}_{2}$ emissions in kilograms for the base case and the four policy cases by subpopulation: simulated values and estimations as linear regression functions; values for a representative $10 \%$ sample. 


$$
\eta_{q, p}=\frac{d q}{d p} \cdot \frac{p_{0}}{\hat{q_{0}}}
$$

where $\frac{d q}{d p}$ is the gradient of the corresponding regression function and $\hat{q_{0}}$ is the estimated initial demand for car trips at $p_{0}=10 \mathrm{ct} / \mathrm{km}$. Applying Eq. 5 to the three subpopulations leads to the following estimated constant price elasticities of car travel demand:

$$
\hat{\eta}_{q, p}^{\text {Urban }}=-0.173, \quad \hat{\eta}_{q, p}^{\text {Inverse.Commuter }}=-0.502, \quad \hat{\eta}_{q, p}^{\text {Commuter }}=-0.692 .
$$

These estimations indicate that e.g. a car user cost increase of $10 \%$ (at the operating point $p_{0}=10 \mathrm{ct} / \mathrm{km}$ ) leads to a reduction in car trips by $1.73 \%$ for inner-urban traffic, by $5.02 \%$ for inverse commuter and by $6.92 \%$ for commuter. Graham and Glaister [2002] present a wide range of fuel price elasticities collected from different studies. When summarizing the different studies, the authors find short-term fuel price elasticities in the range from -0.2 to -0.5 , for Germany around -0.45 . However, the range within Germany goes from -0.25 to -0.86 . The fuel price elasticities found in the present paper are somewhat smaller for inner-urban traffic and within the range for inverse commuter and commuter. Obviously, introducing more choice dimensions into the model, such as location choice or the possibility of dropping activities, is likely to influence the results. At this point, it can be stated that, overall, the model produces reasonable behavioral reactions to car user price increases.

Similarly to Fig. 2, overall $\mathrm{NO}_{2}$ emissions are shown in Fig. 3, again for the base case and the four policy cases. Linear regression lines and functional form are also provided. In this figure, freight traffic emissions are indicated by blue crosses in order to show the big impact of freight traffic emissions on overall emission levels. Since freight demand is not allowed to change the mode to public transport, its emissions stay more or less stable for all policy cases. Only a small reduction can be observed, probably resulting from shorter distances chosen by the router module. Equally to the price elasticities of demand, price elasticities of $\mathrm{NO}_{2}$ emissions are calculated:

$$
\hat{\epsilon}_{q, p}^{\text {Urban }}=-0.219, \quad \hat{\epsilon}_{q, p}^{\text {Inverse.Commuter }}=-0.608, \quad \hat{\epsilon}_{q, p}^{\text {Commuter }}=-0.792 .
$$

The price elasticities are found to be roughly the same for other exhaust emission types under consideration (PM and $\mathrm{SO}_{2}$ ). When comparing them to the price elasticities of car travel demand from above, one can notice a higher elasticity of emissions than of demand for all subpopulations. Thus, an increase in car user costs leads to a higher reduction in emissions than in demand. Two explanations come to mind:

1. An over-proportional fraction of travelers who performed long car trips with high speed levels now change from car to public transport ("biased mode switch effect")

2. Travelers are driving faster on formerly congested roads ("congestion relief effect")

Both explanations are based on the fact that emission levels are usually the lowest for speed levels around $60 \mathrm{~km} / \mathrm{h}$ [see e.g. Maibach et al., 2008, p.58]. Emissions per vehicle kilometer increase for lower but also for higher speed levels, forming an "U-shaped" function with its minimum around $60 \mathrm{~km} / \mathrm{h}$. That is, when mainly trips with high speed levels are reduced (in this case by changing to another mode), overall emissions drop more than demand. The same is true when traffic flow becomes more fluid on formerly congested roads. It seems that the second effect can be observed since our model includes spill-back effects, different traffic states, and individual vehicle characteristics. The following section will address this hypothesis by looking at spatial patterns of changes in travel demand and in air pollutant emissions.

\subsection{Spatial Analysis of Changes in Car Travel Demand and Air Pollutant Emissions}

This section analyzes car travel demand and $\mathrm{NO}_{2}$ emissions on a spatially disaggregated level. Using the features of the emission modeling tool, demand and $\mathrm{NO}_{2}$ emissions can be aggregated per road segment and for any desired time interval. For visual presentation of the spatial effect 
within the urban area of Munich, emissions are spatially smoothed using an Gaussian distance weighting function with a radius of $500 \mathrm{~m}$. Starting with the base case shown in Fig. 4, one notices a high level travel demand (in vehicle kilometers traveled) for the inner ring road, the middle ring road, the main arterial motorways, and the tangential motorway in the north-west of Munich (see Fig. 4a). Travel demand is highly correlated with the level of exhaust emissions (see Fig. 4b). ${ }^{8}$ The population exposure of $\mathrm{NO}_{2}$ emissions near these road sections is critical which is also found in the air pollutant concentration levels at monitoring stations, e.g. at Landshuter Allee [LFU, 2011]. Fig. 5 shows the absolute change in $\mathrm{NO}_{2}$ emissions between the base case and the $100 \%$ price increase (policy case 4). As already presented in Sec. 4.1, the increase in car user costs leads to an important reduction in emission levels. This finding is now confirmed by Fig. 5a which decomposes the overall effect in a spatial distribution. The lesson learned when comparing that picture to Fig. 4 is that roads with the highest potential for emission reductions are located along the corridors with the highest travel demand (and therefore the highest emissions). Fig. 5a also shows that potential gains are considerably larger at the medium and high speed roads than, for example, in the inner urban area. Our approach allows to show such effects on a detailed single-street level while still being applicable to largescale scenarios. This allows both the identification of relevant corridors ("hot spots") and the spatially disaggregated analysis of the consequences of policy measures.

In order to answer the question whether spatial patterns of higher emission elasticities compared to demand elasticities can be observed, Fig. 5b is analyzed. Similar to Fig. 5a, it depicts the absolute difference in emission levels between the base case and the $100 \%$ price increase (policy case 4), but now the absolute change in emissions per vehicle kilometer traveled. Values above zero imply that vehicles produce more emissions per $\mathrm{km}$ traveled, whereas values below zero indicate that vehicles emit less emissions for the same distance. Again, two effects can be observed that correspond with those presented in Sec. 4.1:

1. The "biased mode switch effect" is most important for the main arterial motorways and the tangential motorway in the north-west of Munich: Fig. 5a indicates that overall emissions (and demand) go down on these road segments. But following Fig. 5b, average emissions per vehicle kilometer go up (light gray areas).

2. The "congestion relief effect" seems to be less coherent in Fig. 5b than the first effect. However, dark gray areas indicate that average emissions per vehicle kilometer go down. This means that a reduction in travel demand leads to lower emissions per vehicle kilometer.

The first effect can be interpreted as follows: in the base case, average speeds on motorways were closer to the (emission) optimal speed of $60 \mathrm{~km} / \mathrm{h}$. Fewer vehicles on these roads lead to higher emissions per vehicle kilometer, since travelers drive faster. That is, congestion relief leads to higher emissions per vehicle kilometer. A similar finding was obtained by Newman and Kenworthy [1989], who state that the average traffic speed is correlated positively, and not negatively, with gasoline consumption per capita. The second effect might be interpreted as follows when combining the aggregated and the disaggregated observations: it is likely that due to the reduction in demand, average travel speeds in the corresponding areas get closer to the (emission) optimal speed of $60 \mathrm{~km} / \mathrm{h}$. Emissions along a congested urban road are about twice as high as when traffic is flowing. When car travel demand is reduced and, thereby, the traffic situation on the road segment changes from stop\&go to saturated or even heavy, emissions are more reduced than the flow on that road segment. That is, congestion relief leads to lower emissions per vehicle kilometer especially in urban contexts.

\footnotetext{
${ }^{8}$ Our method currently localizes all emissions on a road segment at the center coordinate. This explains why the tangential motorway in the north-west of Munich is shown as a sequence of filled circles rather than an uninterrupted line.
} 


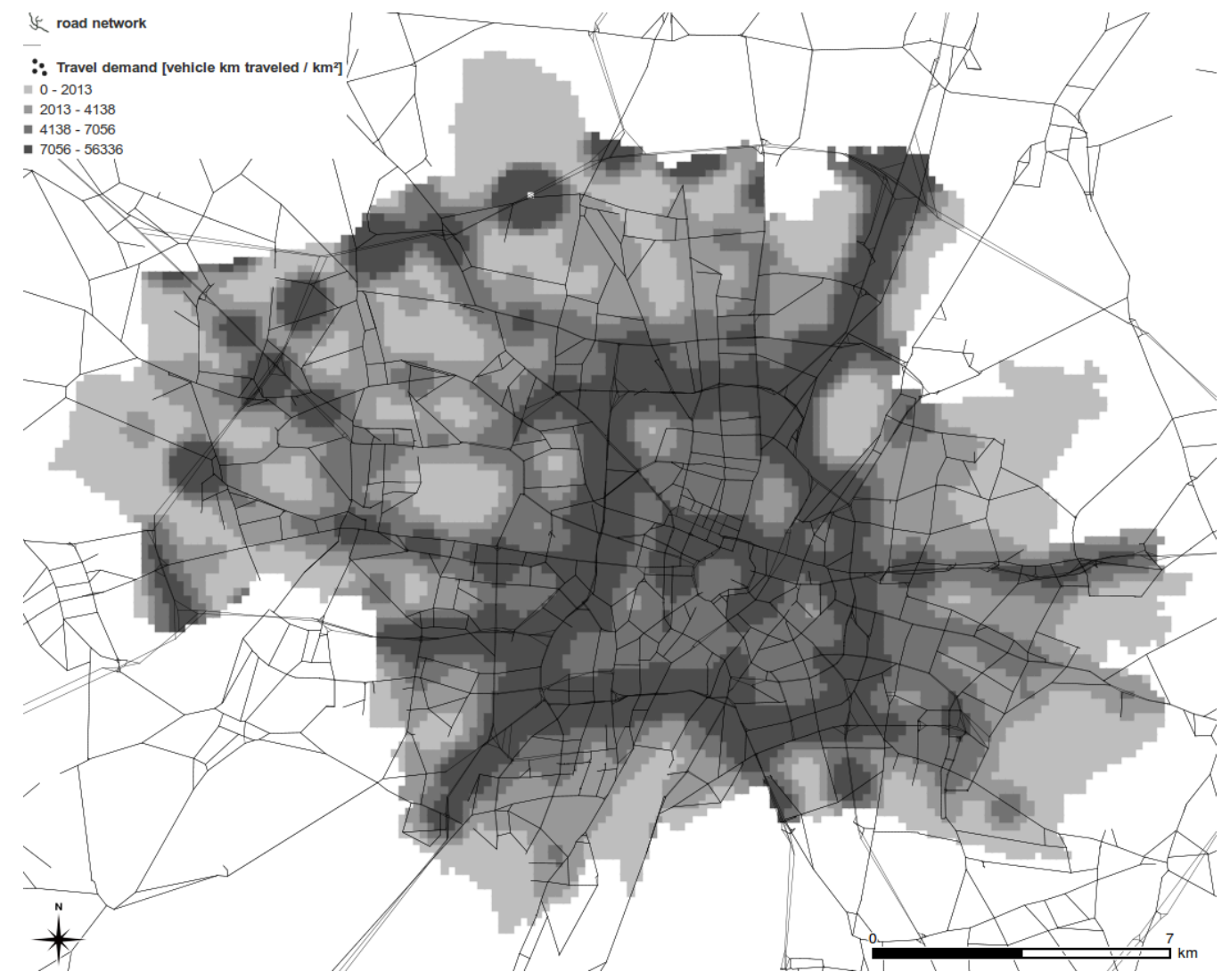

(a) Vehicle kilometers traveled in $v \mathrm{~km} / \mathrm{km}^{2}$

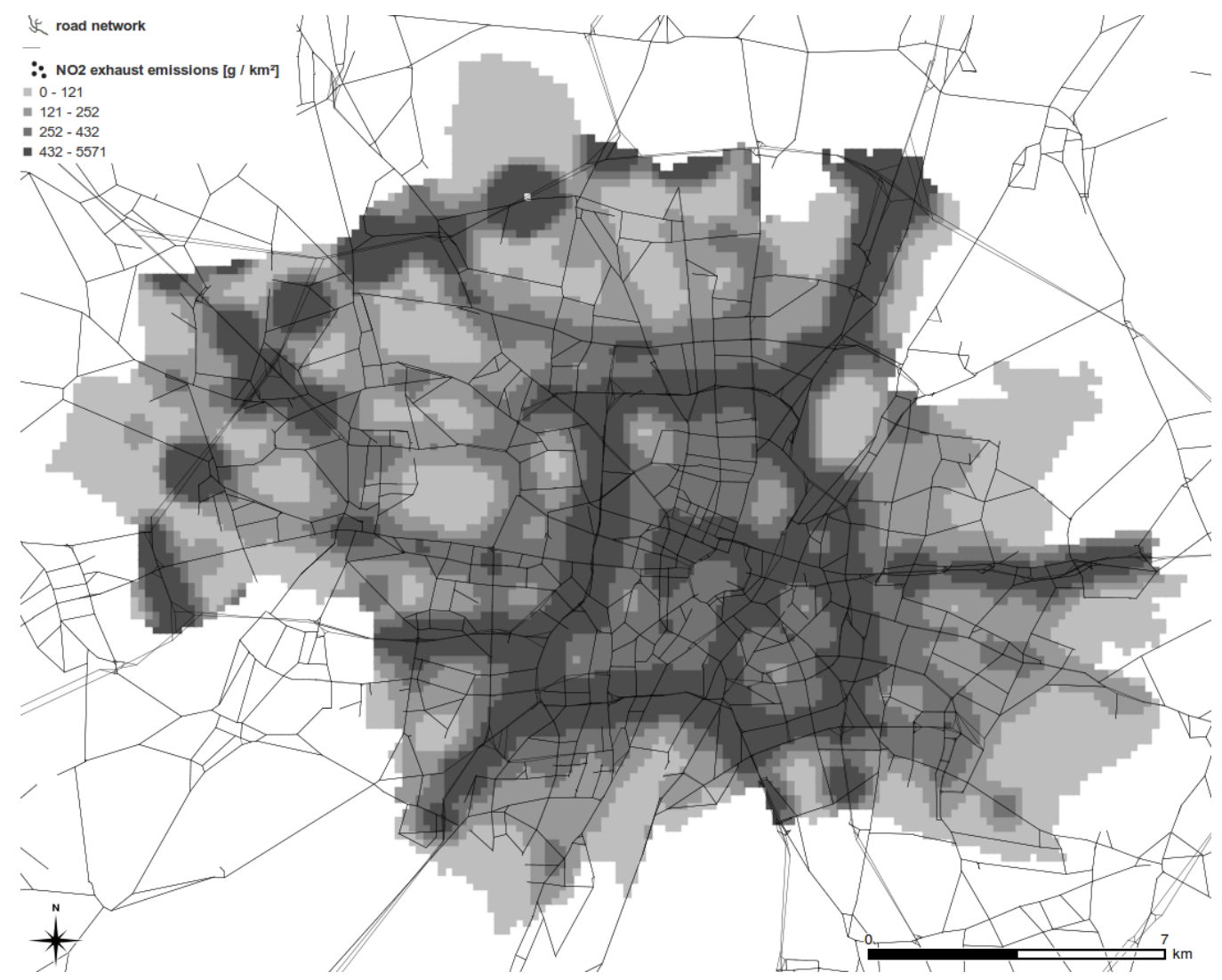

(b) $\mathrm{NO}_{2}$ emissions in $\mathrm{g} / \mathrm{km}^{2}$

Figure 4: Base case: areas with high car travel demand and areas with high $\mathrm{NO}_{2}$ emissions. Plots based on spatial averaging for all road segments. Values for a representative $10 \%$ sample. 


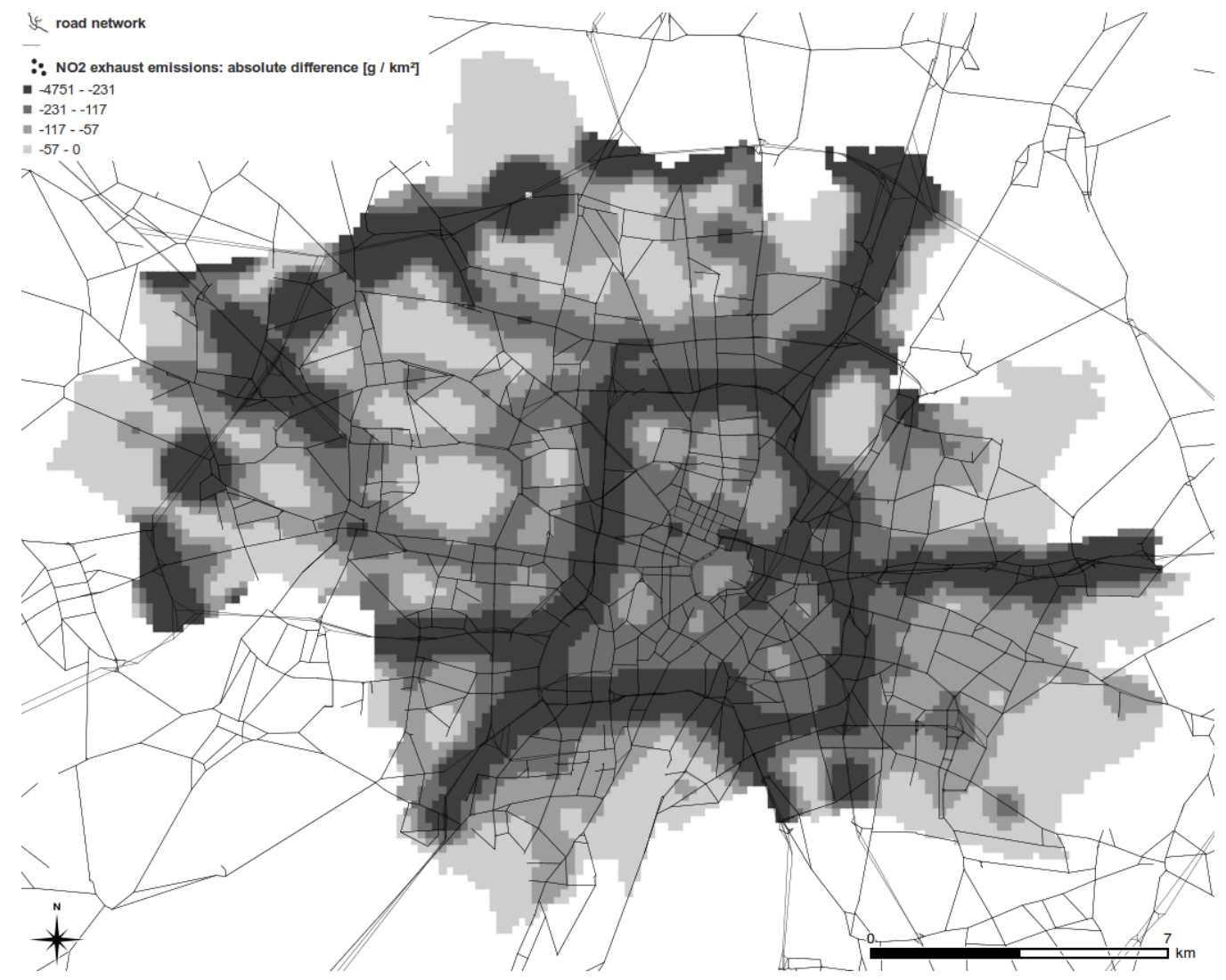

(a) Absolute change in $\mathrm{NO}_{2}$ emissions in $\mathrm{g} / \mathrm{km}^{2}$

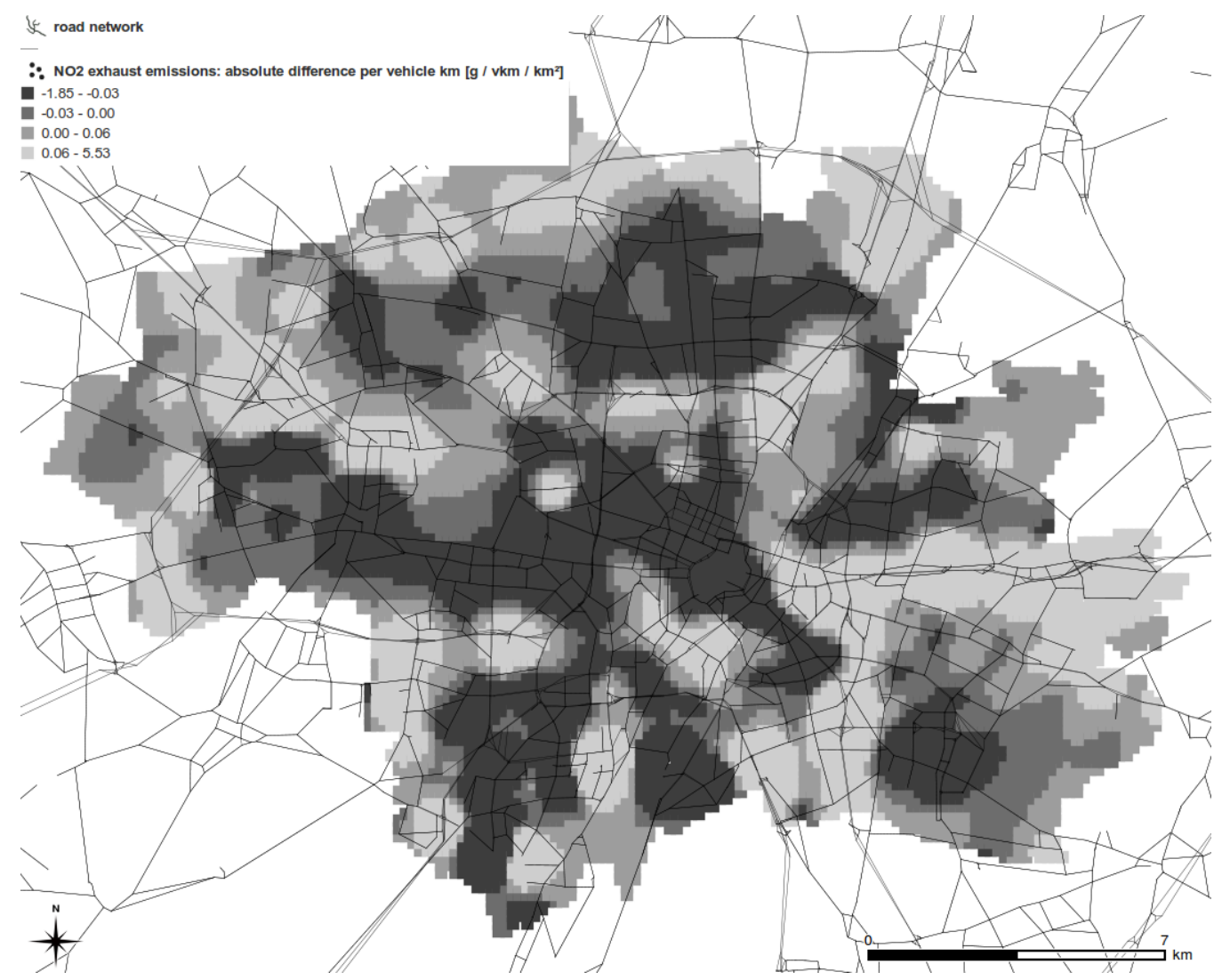

(b) Absolute change in $\mathrm{NO}_{2}$ emissions per vehicle kilometer in $(\mathrm{g} / \mathrm{vkm}) / \mathrm{km}^{2}$

Figure 5: Absolute changes in $\mathrm{NO}_{2}$ emissions between the base case and the $100 \%$ price increase (policy case 4). Plots based on spatial averaging for all road segments. Values for a representative $10 \%$ sample. 


\section{Conclusion}

In this paper, we set up a real-world scenario of the Munich metropolitan area and simulated travel demand of a $10 \%$ sample (around 200'000 individuals) with a large-scale multi-agent simulation. We coupled the simulation with detailed emission factors from the "Handbook Emission Factors for Road Transport", considering the kinematic characteristics derived from the simulation and vehicle attributes obtained from survey data. Since the simulation keeps track of the approximate position and attributes of every traveler's vehicle during every time step, it was possible to map the kinematic characteristics to different traffic situations such as free flow or stop\&go. Thereby, emissions were calculated every time a traveler leaves a road segment, or starts her engine. The mapping of demand (in vehicle kilometers) or emissions back to the road segments was therefore quite straightforward.

We then introduced four policy cases, where user costs for car are rising from $10 \mathrm{ct} / \mathrm{km}$ in four steps up to $20 \mathrm{ct} / \mathrm{km}$. Aggregated price elasticities of demand were found to be in a reasonable range for all subpopulations. Commuters reacted more sensitive to the price increase than inner-urban travelers, e.g. by changing from car to public transport. Price elasticities of $\mathrm{NO}_{2}$ emissions turned out to be higher than those of demand. Two possible explanations were given: first, it might happen that an over-proportional fraction of travelers who performed long car trips with high speed levels changed from car to public transport. We called this the "biased mode switch effect". Second, it seems that travelers are driving faster on formerly congested roads, referred to as the "congestion relief effect".

A spatially more disaggregated analysis allowed to identify so called "hot spots" that bear high potentials for emission reduction: absolute emissions dropped most in many, but not all, areas where travel demand was high. Furthermore, the spatial analysis showed that the "biased mode switch effect" was most important for high-speed arterials and tangential motorways since absolute emissions (and demand) goes down on these road segments, but average emissions per vehicle kilometer go up. Due to higher speeds, fewer vehicles - in this case - lead to higher emissions per vehicle kilometer. The "congestion relief effect" was found to be less coherent in terms of the type of road segment. Nonetheless, some areas showed a reduction in emissions per vehicle kilometer caused by a reduction in demand. Due to higher speeds, fewer vehicles - in this case - lead to lower emissions per vehicle kilometer. Possibly, both effects stem from the fact that the emission optimal speed is usually around $60 \mathrm{~km} / \mathrm{h}$. Measures that allow travelers to drive faster than that will result in higher emissions per vehicle kilometer. However, the relief of congestion seems to bear some potential to reduce emissions on urban roads.

We think that this paper can add valuable information to the transport planning and policy decision making process by providing insights into a new emission calculation model for largescale scenarios. In future studies, we plan to account for more choice dimensions than just route and mode choice. This is likely to influence the results. Also, the robustness of the results needs to be tested by performing sensitivity analysis. A possible extension would be the modeling of air pollutant concentration which could be used to validate simulation results with measured concentration values.

\section{Acknowledgements}

This work was funded in part by the German Research Foundation (DFG) within the research project "Detailed evaluation of transport policies using microsimulation". Important data was provided by the Municipality of Munich, more precisely by 'Kreisverwaltungsreferat München' and 'Referat für Stadtplanung und Bauordnung München'. Our computer cluster is maintained by the Department of Mathematics at Berlin Institute of Technology (TU Berlin). The authors would like to thank two anonymous reviewers for their valuable comments. 


\section{References}

M. André and M. Rapone. Analysis and modelling of the pollutant emissions from european cars regarding the driving characteristics and test cycles. Atmospheric Environment, 43(5): 986-995, 2009. ISSN 1352-2310. doi: 10.1016/j.atmosenv.2008.03.013.

S. Böhme and L. Eigenmüller. Pendlerbericht Bayern. Technical report, IAB, 2006.

N. Cetin, A. Burri, and K. Nagel. A large-scale agent-based traffic microsimulation based on queue model. In Proceedings of the Swiss Transport Research Conference (STRC), Monte Verita, CH, 2003. See www.strc.ch. Earlier version, with inferior performance values: Transportation Research Board Annual Meeting 2003 paper number 03-4272.

Y. Chen, M. Rieser, D. Grether, and K. Nagel. Improving a large-scale agent-based simulation scenario. Technical Report 08-15, 2008.

G. Flötteröd, Y. Chen, and K. Nagel. Behavioral calibration and analysis of a large-scale travel microsimulation. Networks and Spatial Economics, 2011. ISSN 1566-113X. doi: 10.1007/ s11067-011-9164-9.

R. Follmer, U. Kunert, J. Kloas, and H. Kuhfeld. Mobilität in Deutschland - Ergebnisbericht. Technical report, infas/DIW, 2004. See www.kontiv2002.de.

C. Gawron. An iterative algorithm to determine the dynamic user equilibrium in a traffic simulation model. International Journal of Modern Physics C, 9(3):393-407, 1998.

D. J. Graham and S. Glaister. The Demand for Automobile Fuel: A Survey of Elasticities. Journal of Transport Economics and Policy, 36(1):1-25, 2002.

D. Grether, Y. Chen, M. Rieser, and K. Nagel. Effects of a simple mode choice model in a largescale agent-based transport simulation. In A. Reggiani and P. Nijkamp, editors, Complexity and Spatial Networks. In Search of Simplicity, Advances in Spatial Science, chapter 13, pages 167-186. Springer, 2009. doi: 10.1007/978-3-642-01554-0.

D. Guth, C. Holz-Rau, V. Killer, and K. Axhausen. Räumliche Dynamik des Pendelverkehrs in Deutschland und der Schweiz: Das Beispiel München und Zürich. 2010.

M. Hatzopoulou and E. Miller. Linking an activity-based travel demand model with traffic emission and dispersion models: Transport's contribution to air pollution in Toronto. Transportation Research Part D: Transport and Environment, 15(6):315-325, 2010. ISSN 1361-9209. doi: $10.1016 /$ j.trd.2010.03.007.

F. Hülsmann, R. Gerike, B. Kickhöfer, K. Nagel, and R. Luz. Towards a multi-agent based modeling approach for air pollutants in urban regions. In Proceedings of the Conference on "Luftqualität an Straßen", pages 144-166. Bundesanstalt für Straßenwesen, FGSV Verlag GmbH, May 2011. ISBN 978-3-941790-77-3. Also VSP WP 10-15, see www.vsp.tuberlin.de/publications.

ITP/BVU. Prognose der deutschlandweiten Verkehrsverflechtungen 2025. Technical report, 2005. URL http://daten.clearingstelle-verkehr.de/220/.

B. Kickhöfer. Die Methodik der ökonomischen Bewertung von Verkehrsmaßnahmen in Multiagentensimulationen. Diplomarbeit (Diploma Thesis), TU Berlin, Institute for Land and Sea Transport Systems, Berlin, Germany, June 2009. Also VSP WP 09-10, see www.vsp.tuberlin.de/publications.

B. Kickhöfer, D. Grether, and K. Nagel. Income-contingent user preferences in policy evaluation: application and discussion based on multi-agent transport simulations. Transportation, 38: 849-870, 2011. ISSN 0049-4488. doi: 10.1007/s11116-011-9357-6. 
N. Lefebvre and M. Balmer. Fast shortest path computation in time-dependent traffic networks. In Proceedings of the Swiss Transport Research Conference (STRC), Monte Verita, CH, September 2007. See www.strc.ch.

LFU. Überschreitungshäufigkeit für Feinstaub - PM10, Stickstoffdioxid und Schwefeldioxid. Technical report, Bayerisches Landesamt für Umwelt, 2011. URL http://www.1fu .bayern. de/luft/lueb/ueberschreitung_pm10_so2_no2/index.htm. Last access 30.08.2011.

M. Maibach, D. Schreyer, D. Sutter, H. van Essen, B. Boon, R. Smokers, A. Schroten, C. Doll, B. Pawlowska, and M. Bak. Handbook on estimation of external costs in the transport sector. Technical report, 2008.

MVV. Regionaler Nahverkehrsplan für das Gebiet des Münchner Verkehrs- und Tarifverbundes. Technical report, Munich Local Transport Provider, 2007.

P. W. G. Newman and J. R. Kenworthy. Gasoline Consumption and Cities. Journal of the American Planning Association, 55(1):24-37, 1989. doi: 10.1080/01944368908975398.

B. Raney and K. Nagel. An improved framework for large-scale multi-agent simulations of travel behaviour. 2006.

T. Reinhold. Konzept zur integrierten Optimierung des Berliner Nahverkehrs. In Öffentlicher Personennahverkehr. Springer Berlin Heidelberg, 2006. doi: 10.1007/3-540-34209-5\_8.

M. Rieser, D. Grether, and K. Nagel. Adding mode choice to a multi-agent transport simulation. Transportation Research Record: Travel Demand Forecasting 2009, 2132:50-58, 2009. doi: 10.3141/2132-06.

RSB. Municipality of Munich: Referat für Stadtplanung und Bauordnung, 2005.

K. Train. Discrete choice methods with simulation. Cambridge University Press, 2003.

M. Vrtic, N. Schüssler, A. Erath, M. Bürgle, K. Axhausen, E. Frejinger, M. Bierlaire, R. Rudel, S. Scagnolari, and R. Maggi. Einbezug der Reisekosten bei der Modellierung des Mobilitätsverhaltens. Schriftenreihe 1191, Bundesamt für Strassen, UVEK, Bern, CH, 2008. Final Report for Project SVI 2005/004.

M. Weilenmann, J.-Y. Favez, and R. Alvarez. Cold-start emissions of modern passenger cars at different low ambient temperatures and their evolution over vehicle legislation categories. Atmospheric Environment, 43(15):2419-2429, 2009. ISSN 1352-2310. doi: 10.1016/j.atmosenv. 2009.02.005.

\section{Appendix: Simulation Details}

The following paragraphs are meant to present more information about the MATSim simulation approach that is used in this paper. Every step of the iterative loop in Sec. 2.1 is in the following illustrated in more detail.

Plans Generation An agents daily plan contains information about his planned activity types and locations, about duration and other time constraints of every activity, as well as the mode, route, the desired departure time and the expected travel time of every intervening trip (=leg). Initial plans are usually generated based on microcensus information and/or other surveys. The plan that was reported by an individual is in the first step marked as "selected". 
Traffic Flow Simulation The traffic flow simulation executes all selected plans simultaneously in the physical environment and provides output describing what happened to each individual agent during the execution of its plan. The car traffic flow simulation is implemented as a queue simulation, where each road (= link) is represented as a first-in first-out queue with two restrictions [Gawron, 1998, Cetin et al., 2003]: First, each agent has to remain for a certain time on the link, corresponding to the free speed travel time. Second, a link storage capacity is defined which limits the number of agents on the link; if it is filled up, no more agents can enter this link. The public transport simulation simply assumes that traveling takes twice as long as traveling by car on the fastest route in an empty network ${ }^{9}$ and that the travel distance is 1.5 times the beeline distance between the activity locations. public transport is assumed to run continuously and without capacity restrictions [Grether et al., 2009, Rieser et al., 2009].

All other modes are modeled similar to public transport: travel times are calculated based on mode specific travel speed and the distance estimated for public transport. However, the attributes of these modes are not relevant for the present paper since agents are only allowed to switch from car to public transport and the other way around. Trips from the survey that are no car or public transport trips, are held fixed during the learning cycle, thus not changing mode share in any direction.

Output of the traffic flow simulation is a list that describes for every agent different events, e.g. entering or leaving a link, arriving or leaving an activity. These events are written in XML-format and include agent ID, time and location (link or node ID). It is, therefore, quite straightforward to use this disaggregated information for the calculation of link travel times or costs (which is used by the router module), trip travel times, trip lengths, and many more.

Evaluating Plans In order to compare plans, it is necessary to assign a quantitative measure to the performance of each plan. In this work, a simple utility-based approach is used. The elements of our approach are as follows:

- The total utility of a plan is computed as the sum of individual contributions:

$$
V_{\text {total }}=\sum_{i=1}^{n}\left(V_{\text {perf }, i}+V_{t r, i}\right),
$$

where $V_{\text {total }}$ is the total utility for a given plan; $n$ is the number of activities; $V_{\text {perf }, i}$ is the (positive) utility earned for performing activity $i$; and $V_{t r, i}$ is the (usually negative) utility earned for traveling during trip $i$. Activities are assumed to wrap around the 24-hoursperiod, that is, the first and the last activity are stitched together. In consequence, there are as many trips between activities as there are activities.

- A logarithmic form is used for the positive utility earned by performing an activity:

$$
V_{\text {perf }, i}\left(t_{\text {perf }, i}\right)=\beta_{\text {perf }} \cdot t_{*, i} \cdot \ln \left(\frac{t_{p e r f, i}}{t_{0, i}}\right)
$$

where $t_{\text {perf }}$ is the actual performed duration of the activity, $t_{*}$ is the "typical" duration of an activity, and $\beta_{\text {perf }}$ is the marginal utility of an activity at its typical duration. $\beta_{\text {perf }}$ is the same for all activities, since in equilibrium all activities at their typical duration need to have the same marginal utility. $t_{0, i}$ is a scaling parameter that is related both to the minimum duration and to the importance of an activity. As long as dropping activities from the plan is not allowed, $t_{0, i}$ has essentially no effect.

- The disutility of traveling used for simulations is estimated from survey data which is explained in Sec. 3.2.

9 This is based on the (informally stated) goal of the Berlin public transport company to generally achieve door-to-door travel times that are no longer than twice as long as car travel times. This, in turn, is based on the observation that non-captive travelers can be recruited into public transport when it is faster than this benchmark Reinhold [2006]. 
In principle, arriving early or late could also be punished. For the present paper, there is, however, no need to do so, since agents are not allowed to reschedule their day by changing departure times. Arriving early is already implicitly punished by foregoing the reward that could be accumulated by doing an activity instead (opportunity cost). In consequence, the effective (dis)utility of waiting is already $-\beta_{\text {perf }} \cdot t_{*, i} / t_{\text {perf }, i} \approx-\beta_{\text {perf }}$. Similarly, that opportunity cost has to be added to the time spent traveling.

Learning After evaluating daily plans in every iteration, a certain number of randomly chosen agents is forced to re-plan their day for the next iteration. This learning process is, in the present paper, done by two modules corresponding to the two choice dimensions available: a module called "router" for choosing new routes on the road network and a module called "subtour mode choice" for choosing a new transport mode for a car or public transport trip. The router module bases its decision for new routes on the output of the car traffic flow simulation and the knowledge of congestion in the network. It is implemented as a time-dependent best path algorithm [Lefebvre and Balmer, 2007], using generalized costs (= disutility of traveling) as input. The sub-tour mode choice module changes the transport mode of a car sub-tour to public transport or from a public transport sub-tour to car. A sub-tour is basically a sequence of trips between activity locations. However, the simulation needs to make sure that a car can only be used if it is parked at the current activity location. Thus, a sub-tour is defined as a sequence of trips where the transport mode can be changed while still being consistent with the rest of the trips. It is e.g. assured that a car which is used to go from home to work in the morning needs to be back at the home location in the evening. If the car remains e.g. at the work location in order to use it to go for lunch, then the whole sub-tour of going to work and back needs to be changed to public transport. 